\title{
PERANCANGAN CORPORATE IDENTITY SEBAGAI MEDIA PENGENALAN IKM BATIK TULIS MANDANGIN
}

\author{
Yekti Asmoro Kanthi ${ }^{1}$, Rahmat Kurniawan ${ }^{2}$, Aliyuddin ${ }^{3}$ \\ Sekolah Tinggi Informatika dan Komputer dan Indonesia Malang ${ }^{12} 3$ \\ corresponding author: Yekti Asmoro Kanthi, yektiasmoro@stiki.ac.id, Malang, Indonesia
}

\begin{abstract}
Abstrak. Penelitian ini bertujuan untuk merancang identitas perusahaan untuk meningkatkan kesadaran akan brand tersebut. Batik Tulis Mandangin merupakan hasil karya masyarakat lokal dengan memanfaatkan alat sederhana dan pengambilan motif berorientasi pada alam sekitar. Batik Tulis Mandangin merupakan sebuah IKM Desa Pulau Mandangin yang harus dijaga dan dibangun untuk meningkatkan perekonomian masyarakat. Permasalahan yang terjadi pada industri ini adalah belum adanya identitas visual agar mudah dikenali oleh masyarakat luas. Sebagai upaya mengatasi permasalahan tersebut peneliti membuat sebuah perancangan corporate identity. Tahapan proses perancangan ini di antaranya (1) latar belakang masalah perancangan, (2) identifikasi, (3) analisis kesimpulan, (4) sintesis, (5) konsep perancangan, (6) konsep tata desain corporate identity, dan (7) desain final. Hasil penelitian menunjukkan bahwa logo yang tepat bagi IKM Batik Tulis Mandangin ialah dengan mengangkat nilai-nilai lokal dan sumber daya alam Pulau Mandangin berupa penggunaan warna-warna cerah dan bentuk dasar ombak, motif batik serta inisial M. Setelah logo dirancang, pengaplikasiannya pada media perlu diatur agar konsisten sehingga mudah dikenali, maka GSM dirancang. Media pendukung juga dibuat sebagai solusi atas permasalahan promosi pemasaran.
\end{abstract}

Kata Kunci: perancangan, corporate identity, IKM batik tulis Mandangin, logo, media

\begin{abstract}
This research aimed at designing corporate identity for Batik Tulis Mandangin to increased its brand awareness. Batik Tulis Mandangin is the works of the local community by using simple tools and making natural-oriented motifs. Batik Tulis Mandangin is a Mandangin Island Village IKM that must be maintained and built to improve the community economy. The problem that occurs in this industry is that there is no visual identity so that it is easily recognized by the wider community. In an effort to overcome these problems, we make a corporate identity design. The stages of design process are (1) design problem background, (2) identification, (3) conclusion analysis, (4) synthesis, (5) design concept, (6) the concept of corporate identity design, and (7) the final design. The results show that the appropriate logo for IKM Batik Tulis Mandangin is to adopt local values and natural resources of Mandangin Island in the form of the use of bright colors and basic shapes namely wave, batik motifs and the initials $M$. The logo was designed, it needs to be consistent with its application on the media so that it is easily recognized, then GSM is also designed. Supporting media is also designed as a solution to marketing promotion problems.
\end{abstract}

Keywords: design, corporate indentity, IKM Batik Tulis Mandangin, logo, media 


\section{Pendahuluan}

Batik merupakan salah satu warisan budaya yang wajib untuk dijaga. Menurut Parmono (2013) batik sebagai salah satu karya seni budaya bangsa Indonesia yang telah mengalamiperkembangan seiring dengan perjalanan waktu. Perkembangan yang terjadi membuktikan bahwa batik sangat dinamis dan dapat menyesuaikan dalam dimensi ruang, waktu, dan bentuk. Terdapat beberapa macam jenis batik yang ada di Indonesia salah satunya adalah Batik Tulis Madura. Batik Madura tergolong batik pesisir. Batik pesisir Madura tersebut, membuat produksi Batik Tulis Madura berkembang pesat pada tahun 1870 (Ishwara, Yahya, and Moeis 2011). Terdapat beberapa produksi batik tulis yang ada di Madura, antaranya Batik Sumenep, Pamekasan, dan Bangkalan (Marijan and Supriyatno 2013). Dilansir dari radarmadura.id (16 November 2019) dapat diketahui bahwa Pemerintah Kabupaten Sampang memiliki ciri khas batik yang diketahui dengan motif sejarah.

Berdasarkan Hasil dari observasi yang dilakukan oleh perancang pada Minggu, 17 November 2019 di lokasi Industri Batik Tulis Mandangin dapat diketahui bahwa melalui Mahasiswa KKN dari UNAIR yang bekerjasama dengan pihak pemerintahan desa mengadakan pelatihan tentang pembuatan Batik Tulis di Desa Mandangin. Kegiatan dari mahasiswa KKN tersebut menjadi cikal bakal berdirinya Industri Batik Tulis Mandangin yang diwadahi oleh pemerintah Sampang. Menurut Kimbal (2015) pemerintah dan para pakar ekonomi mengakui bahwa ekonomi Indonesia mampu terhindar dari kehancuran yang parah dikarenakan kekuatan dan daya tahan jutaan usaha kecil dan kegiatan perekonomian tradisi rakyat lainnya. Peningkatan Industri Kecil Menengah (IKM) menjadi salah satu bukti terlaksananya ekonomi kreatif di Indonesia. Batik Tulis Mandangin merupakan hasil karya masyarakat lokal dengan memanfaatkan alat sederhana, begitu juga motifnya yang beriontasi pada alam sekitar membuat banyak perhatian konsumen, dan Batik Tulis Mandangin juga merupakan IKM satu satunya di Desa Pulau Mandangin, Sehingga IKM Batik Tulis Mandangin harus tetap dijaga dan dibangun untuk menambah ekonomi masyarakat.

Berdasarkan wawancara yang dilakukan oleh peneliti pada Minggu, 17 November 2019 dengan Idrus sebagai pemilik industri dapat diketahui bahwa batik ini berdiri pada akhir tahun 2014 sampai sekarang. Perkembangan Mandangin saat ini hanya dikenal beberapa wilayah, seperti Kabupaten Sampang, Kabupaten Bangkalan, Kabupaten Blitar, dan Kabupaten Trenggalek. Jangkauan pemasaran Batik Tulis Mandangin masih dapat dikatakan sempit. Keterbatasan pemasaran tersebut mempengaruhi proses penjualan industri, sehingga rata-rata penjualan per bulan masih dikatakan rendah.

Berdasarkan testimoni para konsumen pada tanggal 20 Mei 2020 menyatakan bahwa, Batik Tulis Mandangin mempunyai kualitas yang bagus. Selain itu, motif yang dipilih Batik Tulis Mandangin memiliki ciri khas yang unik dan bernilai jual tinggi. Pembeli merasa sangat puas terhadap produk yang didapatkan dengan harga terjagkau. Hal tersebut tidak sebanding dengan hasil penjualan yang rendah. Permasalahan tersebut dapat disimpulkan bahwa keterbatasan pemasaran tersebut dikarenakan pengrajin masih balum mengerti pentingnya corporate identity sebagai media pengenalan dalam proses pemasaran, sehingga Batik Tulis Mandangin memerlukan corporate identity sebagai media pengenalan untuk memudahkan pemasaran dan memudahkan target audien dalam mengingatnya. Hal ini juga sejalan dengan pendapat Argenti (2010) yang menyatakan bahwa Identitas perlu diperlakukan sepantasnya agar konsumen selalu membuat pembedaan-pembedaan tentang produk setiap perusahaan untuk membentuk citra perusahaan dan identitas menjadi pembeda yang semakin kuat.

Corporate identity adalah bentuk visual yang akan menjadi identitas dari sebuah industri (Cholil 2018). Sebagai identitas industri, corporate identity dapat mempengaruhi perkembangan dan arah industri, termasuk laba jangka panjang. Corporate identity biasanya digunakan sebagai 
pembeda oleh industri. Salah satu bentuk fisik dari corporate identity adalah logo. Namun, sejalan dengan itu Batik Tulis Mandangin masih belum memiliki corporate identity yang kuat sebagai media pengenalan agar mampu bersaing di pasaranan. Selain itu, dengan adanya logo merupakan Langkah awal dalam membangun brand awareness sebuah produk. Dalam branding, yang dikelola adalah brand touchpoints dan brand identity dari sebuah entitas. Harapannya, dengan secara konsisten dan intensif, branding dapat meningkatkan loyalitas audience atau pelanggan (Wheeler 2009). Dengan logo yang menarik dan outstanding, masyarakat akan mudah mengingat produk tersebut untuk jangka panjang.

Menurut keterangan narasumber, permasalahan yang paling signifikan adalah terkait tentang jangkauan pemasaran. Identitas dalam pemasaran dapat meningkatkan minat konsumen dan sebagai media promosi untuk memperkenalkan atau menambah nilai daya tarik Batik Tulis Mandangin. Oleh karena itu, perancang terdorong untuk membuat perancangan tentang corporate identity sebagai media pengenalan IKM Batik Tulis Mandangin.

Batasan Perancangan memfokuskan pembahasan dalam merancang corporate identity sebagai media pengenalan IKM Batik Tulis Mandangin yakni memfokuskan dalam perancangan logo IKM Batik Tulis Mandangin beserta media pendukungnya. Untuk membangun citra identitas visual ini dibangun berdasarkan keanekaragaman, ciri khas dan keunikan baik dari produk maupun dari lingkungan. Selain itu, proses perancanga ini juga dilengkapi beberapa data pendukung terkait sejarah, pemasaran dan perkembangan Batik Tulis Mandangin ini.

Diharapkan perancangan yang telah dilakukan dapat membantu industri dalam membangun sebuah identitas UMKM, sehingga industri dapat mudah dikenal oleh masyarakat. Selain itu, juga Membantu industri dalam pemasaran melalui perancangan corporate identity yang dilakukan oleh perancang. Dengan logo dan corporate identity yang baik dan tepat maka dapat menimbulkan dampak positif kepercayaan konsumen terhadap perusahaan (Julita, Bangsa, and Yudani 2013).

\section{Metode}

Metode perancangan ini mengacu pada langkah-langkah Sanyoto (2006) sebagai acuan penulis dalam melakukan perancangan corporate identity IKM Batik Tulis Mandangin. Langkahlangkah perancangan tersebut telah disesuaikan dengan konsep perancangan yang diterapkan oleh peneliti. Berikut modifikasi langkah-langkah perancangan sebagai berikut, (1) latar belakang masalah perancangan, (2) identifikasi, (3) analisis kesimpulan, (4) sintesis, (5) konsep perancangan, (6) konsep tata desain corporate identity, dan (7) desain final. Perancangan corporate identity ini menggunakan dua sumber data, yaitu sumber data primer dan sumber data sekunder. Menurut Sugivono (2014) sumber data primer merupakan sumber data yang diperoleh langsung dari sumber asli (tidak melalui media atau perantara). Sumber data primer dalam penelitian ini diperoleh secaraa langsung dari perusahaan melalui wawancara dan kuesioner dari pemilik perusahaan. Dalam perancangan ini sumber data primer yang digunakan adalah pemilik Batik Tulis Mandangin dan tempat industri Batik Tulis Mandangin. Sumber data sekunder dalam perancangan ini diperoleh dari buku-buku sebagai penunjang argumen peneliti, jurnal penelitian terdahulu, dan website.

Teknik pengumpulan data dalam perancangan ini antara lain observasi, wawancara, dokumentasi, dan kuesioner; 1 ) Observasi sangat penting dilakukan untuk membantu peneliti menemukan permasalahan hingga mencari data tentang industri yang dilaksanakan pada hari Minggu, 17 November 2019-20 Mei 2020. Sehingga, peneliti memilih topik perancangan corporate identity IKM Batik Tulis Mandangin; 2) Wawancara dilakukan perancang menemukan permasalahan yang harus diatasi. Dalam peranan ini dilakukan wawancara langsung kepada 
Idrus dan Hapideh selaku pemiliki industri Batik Tulis Mandangin; 3) Dokumentasi Dalam perancangan ini penulis mengumpulkan data berupa dokumentasi karya Batik Tulis Mandangin, dan buku-buku terkait dengan kajian dalam perancangan ini; 4) Kuesioner, responden yang diambil yaitu sebanyak 15 responden yang mewakili perdusun terdapat 5 responden dengan latar belakang berbeda seperti tokoh masyarakat, tokoh agama, mahasiswa, masyarakat, dan guru. Analisis data dalam perancangan ini menggunakan metode analisis $5 \mathrm{~W}+1 \mathrm{H}$.

\section{Hasil dan Pembahasan}

\section{Identifikasi data}

Data IKM

Berdasarkan hasil identifikasi, diperoleh data bahwa nama industri resmi IKM adalah Batik Tulis Mandangin. IKM Batik tulis Mandangin beralamat di Dusun Candin, RT/RW 001/01, Desa Pulau Mandangin, Kecamatan Sampang, Kabupaten Sampang. Pemilik IKM atas nama Idrus. Industri batik tulis mandangin berdiri pada tanggal 14 Desember 2014. Pada saat pendirian industri Batik Tulis Mandangin didukung oleh pemerintah desa. Ide pendirian batik tulis Mandangin ini berasal dari kegiatan pelatihan membuat batik tulis yang dilakukan oleh mahasiswa KKN dari UNAIR. Perkembangan tahun pertama industri ini diawasi oleh pemerintah desa, setelah itu industri diserahkan sepenuhnya kepada Idrus. Tujuan pembuatan Batik Tulis Mandangin ini adalah untuk mengangkat lokalitas Pulau Mandangin dan meningkatkan perekonomian masyarakat.

\section{Data Produk}

Tabel 1 Data produk batik tulis Mandangin

\begin{tabular}{lcl}
\hline Jenis produk & Bahan baku produk & \multicolumn{1}{c}{ Keunggulan Produk } \\
\hline Kain Batik & Kain mori, lilin malam batik, air & Motif-motif yang diambil dari sumber daya \\
(ukuran 2,1m $\times 1,05 \mathrm{~m})$ & tawar, dan alat- alat seperti anting, \\
kompor, dan lain lain & $\begin{array}{l}\text { alam yang menjadi ciri khas Pulau Mandangin } \\
\text { seperti ikan, udang, kepiting, cumi, batu } \\
\text { candin, dan daun soekarno. }\end{array}$ \\
\hline
\end{tabular}

Tabel 2 Daftar Harga Batik Tulis Mandangin 17 November 2019-20 Mei 2020

\begin{tabular}{|c|c|c|}
\hline Motif & Warna & Harga \\
\hline $\begin{array}{l}\text { Batu Candin } \\
\text { (ukuran } 2,1 \mathrm{~m} \times 1,05 \mathrm{~m} \text { ) }\end{array}$ & Hitam & Rp. 170.000 \\
\hline Hewan Laut (ikan, udang, kepiting, cumi) & Biru & Rp. 150.000 \\
\hline \multirow[t]{4}{*}{ (ukuran $2,1 \mathrm{~m} \times 1,05 \mathrm{~m}$ ) } & Army & Rp. 150.000 \\
\hline & Merah & Rp. 155.000 \\
\hline & Putih & Rp. 150.000 \\
\hline & Coklat & Rp. 150.000 \\
\hline $\begin{array}{l}\text { Kambing } \\
\text { (ukuran } 2,1 \mathrm{~m} \times 1,05 \mathrm{~m} \text { ) }\end{array}$ & Hitam & Rp. 175.000 \\
\hline Daun Soekarno & Hitam Kombinasi & Rp. 175.000 \\
\hline (ukuran 2,1m X 1,05m) & Merah & Rp. 175.000 \\
\hline
\end{tabular}

\section{Hasil Rancangan}

Logo

Berdasarkan hasil perancangan corporate identity IKM Batik Tulis Mandangin diperoleh desain final yang sudah disesuaikan dengan perbandingan 1:1. Tahapan pembuatan logo melalui proses brainstorming. Tahap ini bertujuan untuk memperoleh insight atau keyword. 
Pengembangan keyword dilakukan dengan memikirkan berbagai kemungkinan munculnya katakata yang jika divisualisasikan dapat berbentuk simbol, indeks dan ikon (Muntazori, Listya, and Qeis 2019). Menurut Paramita and Kusumandyoko (2019) logo yang baik dapat mencerminkan dan mengangkat citra entitasnya sekaligus membedakannya dengan yang lain. Dalam perancangan logo batik Tulis Mandangin, beberapa keyword atau insight diperoleh berdasarkan hasil dari brainstorming pulau mandangin dan karakteristiknya. Logo IKM Batik Tulis Mandangin menggunakan bentuk dasar dari tiga objek, yaitu ombak, huruf $M$, dan motif batik itu sendiri. Setiap objek memiliki filosofi tersendiri, berikut penjabarannya (1) ombak merupakan representasi dari air, dimana Pulau Mandangin merupakan sebuah pulau kecil yang dikelilingi oleh lautan dan sebagian mata pencaharian masyarakat disana adalah nelayan. (2) huruf $M$ menunjukkan inisial dari kata Mandangin, kata Mandangin merupakan nama brand IKM tempat produksi batik tersebut. (3) motif batik identik dengan stilasi ragam hias yang menjadi elemen utama dalam desain batik. Motif batik digunakan untuk mempertegas bahwa logo tersebut sebagai identitas industri batik.

Bentuk font yang digunakan dalam logo ini adalah San serif tegak. Penggunaan jenis font tersebut dimaksudkan agar logo tampil lebih elegan. Selain itu, tulisan juga mudah terbaca dan menampilkan nilai estetika. Penyusunan tulisan yang sedemikian rupa dimaksudkan untuk menonjolkan keseimbangan dan keestetikaan. Keseimbangan dan informasi, harus dapat berjalan bersama. Tanpa adanya keseimbangan dalam karya desain membuat desain tersebut kurang mutlak dan akan mengganggu pengamatan, sebaliknya sebuah desain yang indah dan seimbang jugalah tidak dapat dikatakan berhasil apabila pengamat tidak mampu memperoleh informasi apapun darinya (Wijaya 1999).

Warna termasuk salah satu unsur keindahan dalam seni dan desain selain unsur-unsur visual yang lain (Darmaprawira 2002). Warna dengan komposisi yang baik akan menimbulkan harmonisasi dan estetika. Selain itu, penggunaan warna memiliki kesan psikologis tertentu bagi pengamat. Komposisi warna yang digunakan pada Batik Tulis Mandangin adalah biru, ungu, dan ungu muda. Pemilihan warna tersebut juga memiliki filosofi tersendiri. Warna menimbulkan kemenarikan baik secara fisik maupun psikologis audiens yang melihatnya, memisahkan kategori atau antar bagian dalam konten sehingga mempermudah pemahaman, menyatukan keseluruhan bagian, memberi penekanan pada konten tertentu yang ingin ditonjolkan, menciptakan kontras antara figure dengan latar belakang (Listya 2019).

Berikut filosofi dari setiap warna, (1) Biru tua menunjukkan warna dasar IKM Batik Tulis Mandangin, karena warna biru merupakan warna laut dimana masyarakat Mandangin rata-rata bermata pencarian sebagai nelayan, selain itu warna biru menunjukkan kesan sejuk dan tenang. Kesan tersebut selaras dengan suasana pulau Mandangin yang jauh dari hiruk pikuk perkotaan. (2) ungu merupakan warna khas dari motif Batik Tulis Mandangin, dan (3) ungu muda merupakan gradasi dari warna biru dan ungu. Secara keseluruhan warna biru tua, ungu tua dan ungu muda merupakan perpaduan warna yang harmonis karena ketiga warna tersebut terdapat dalam satu deret warna analogus. Berikut hasil perancangan logo Batik Tulis Mandangin :

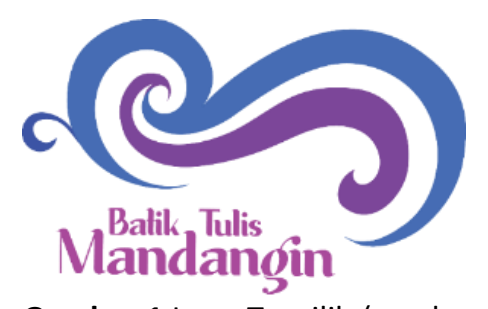

Gambar 1 Logo Terpilih (sumber: Dokumentasi Perancang) 
Graphic Standard Manual (GSM)

Graphic Standard Manual (GSM) terdiri dari logo konfigurasi, logo grid, minimum logo, ruang kosong, grayscale, warna logo, full color, color background, font type, incorrect logo, incorrect color. Berikut bentuk detail dari Graphic Standard Manual (GSM) sebagai berikut:

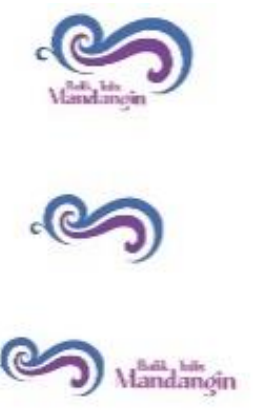

Gambar 3 Logo Konfigurasi

(sumber: Dokumentasi Perancang)

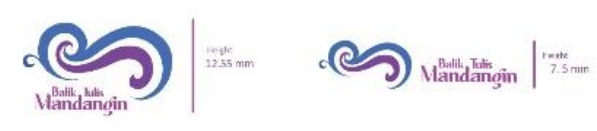

Gambar 5 Minimum Logo

(sumber: Dokumentasi Perancang)

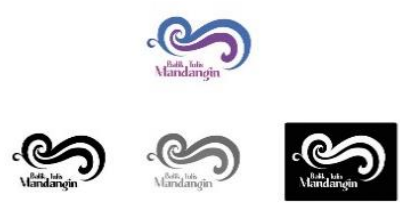

Gambar 8 Logo Grayscale (sumber: Dokumentasi Perancang)

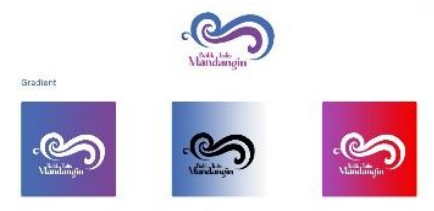

Gambar 10 Full Color

(sumber: Dokumentasi Perancang)

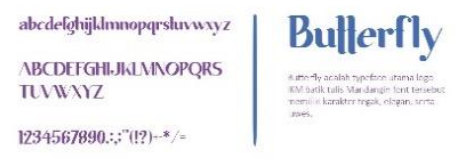

Gambar 12 Font Type

(sumber: Dokumentasi Perancang)

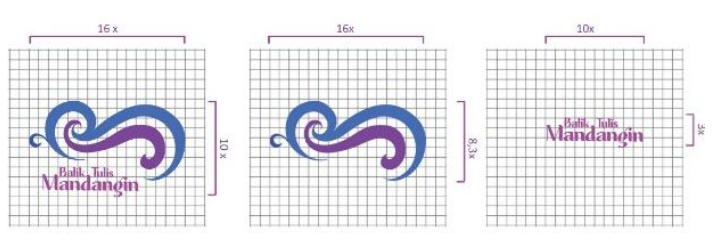

Gambar 4 Logo Grid

(sumber: Dokumentasi Perancang)

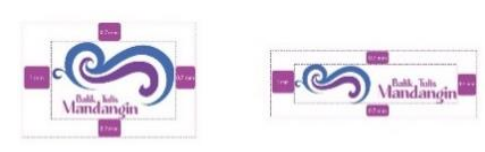

Gambar 6 Ruang Kosong

(sumber: Dokumentasi Perancang)

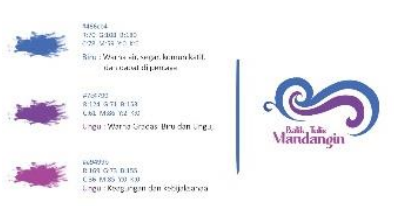

Gambar 9 Warna Logo

(sumber: Dokumentasi Perancang)

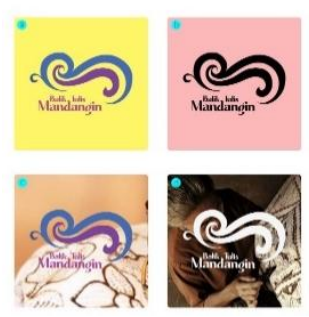

Gambar 11 Color Background

(sumber: Dokumentasi Perancang)

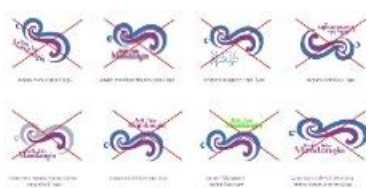

Gambar 13 Incorrect Logo

(sumber: Dokumentasi Perancang) 

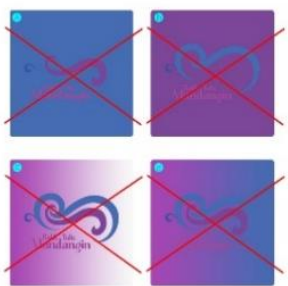

Gambar 14 Incorrect Warna

(sumber: Dokumentasi Perancang)

\section{Implementasi media}

Implementasi media merupakan proses perwujudan logo pada media - media tertentu. Media yang dipilih adalah media yang mempunyai keterkaitan secara fungsi dan mendukung produk. Implementasi media juga berperan sebagai media promosi baik secara langsung maupun tidak langsung. Media - media yang dipilih antara lain :

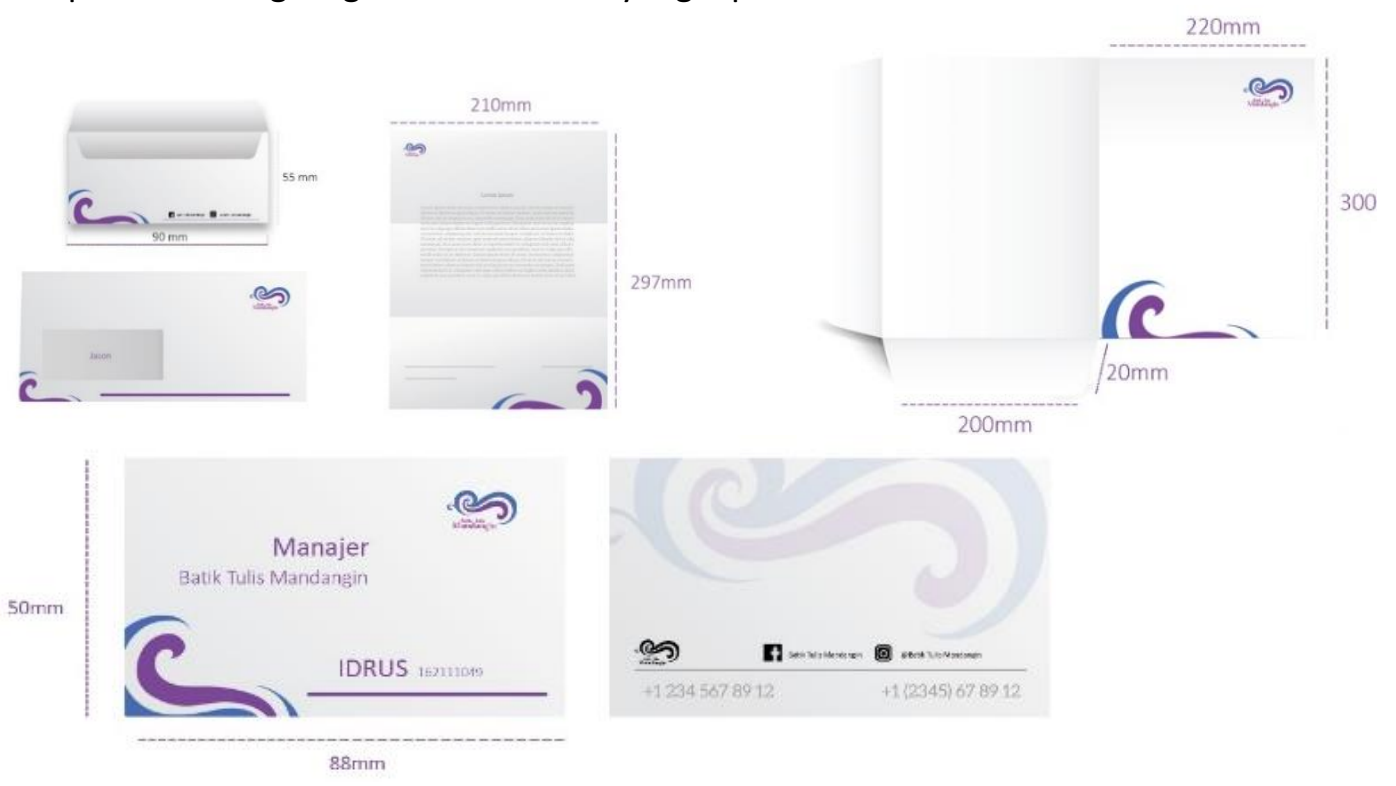

Gambar 15 Stationary

(sumber: Dokumentasi Perancang)

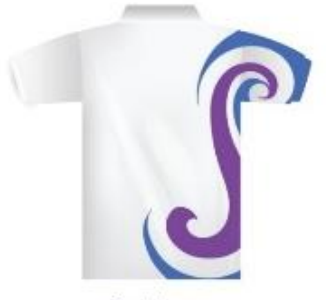

Belakang

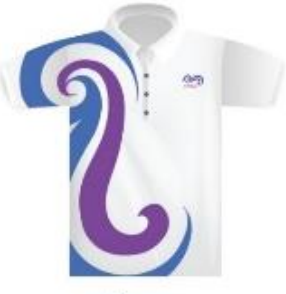

Depan

Gambar 16. Baju Seragam

(sumber: Dokumentasi Perancang)

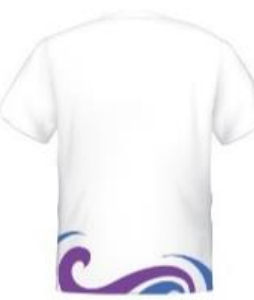

Belakang

Gambar 17. Kaos Seragam

(sumber: Dokumentasi Perancang) 


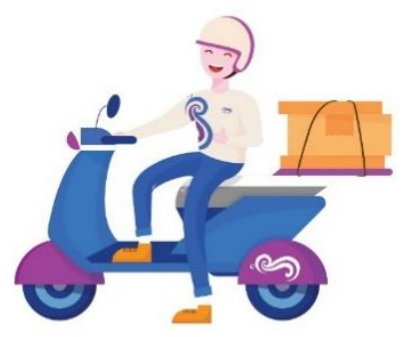

Gambar 18 Sepeda Motor

(sumber: Dokumentasi Perancang)

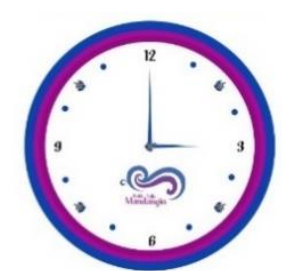

Gambar 20 Jam

(sumber: Dokumentasi Perancang)

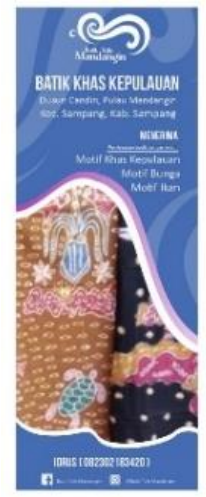

Gambar 22 X-Banner

(sumber: Dokumentasi Perancang)

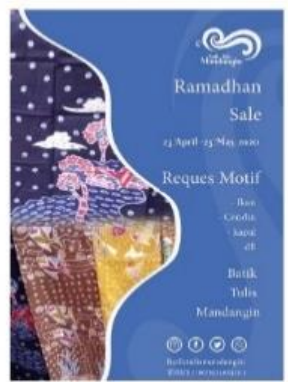

Gambar 24 Brosur

(sumber: Dokumentasi Perancang)

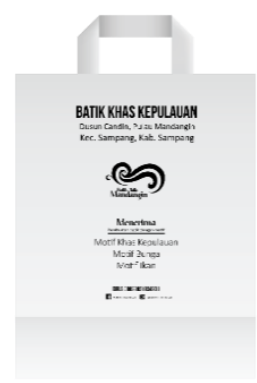

Gambar 19 Paper Bag

(sumber: Dokumentasi Perancang)

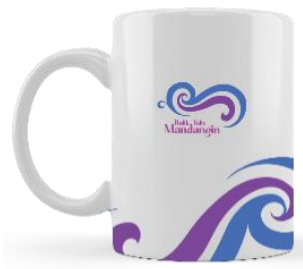

Gambar 21 Mug

(sumber: Dokumentasi Perancang)

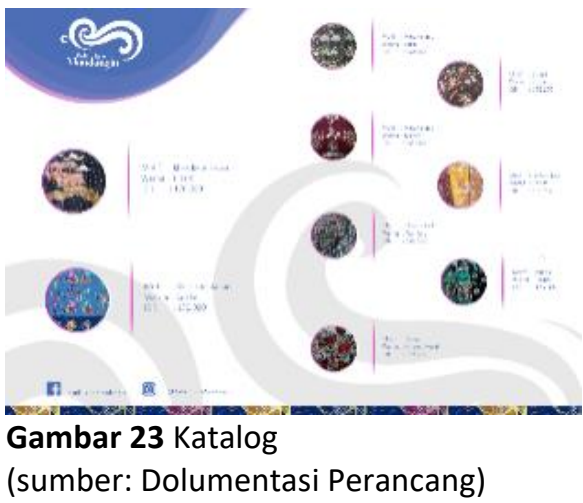




\section{Simpulan}

Data hasil observasi di lapangan dan wawancara menunjukkan bahwa industri Batik Tulis Mandangin belum memiliki identitas yang kuat untuk dikenalkan kepada masyarakat. Industri Batik Tulis Mandangin memerlukan sebuah corporate identity yang dapat mewakili karakter dari industri Batik Tulis Mandangin agar mudah dikenali.

Hasil akhir dari Perancangan corporate identity yang dilakukan pada industri Batik Tulis Mandangin berupa logo. Dalam proses pembuatan logo memerlukan tata desain untuk menghasilkan karya seni yang memiliki nilai estetika, menarik perhatian, dan menyenangkan bagi target audience. Proses pembuatan logo melalui beberapa tahap, yaitu brainstorming, idea layout, rough layout, dan comprehensive layout.

Konsep perancangan yang digunakan pada perancangan corporate identity sebagai media pengenalan IKM Batik Tulis Mandangin ini menggunakan gaya flat design karena desain mengandung unsur 2 dimensi, minimalis, dan menggunakan warna yang cerah dengan mengangkat nilai-nilai lokal dan sumber daya alam Pulau Mandangin. Pada konsep perancangan ini menggunakan warna biru, ungu, dan ungu muda. Logo IKM Batik Tulis Mandangin menggunakan bentuk dasar dari tiga objek, yaitu ombak, huruf $M$, dan motif batik. Setiap objek memiliki filosofi tersendiri, berikut penjabarannya (1) ombak merupakan representasi dari air, dimana Pulau Mandangin merupakan sebuah pulau kecil yang dikelilingi oleh lautan, (2) huruf M menunjukkan inisial dari kata Mandangin, dan (3) motif batik merupakan salah satu bentuk yang mempertegas bahwa logo tersebut sebagai identitas industri batik.

Sebuah perancangan memerlukan sebuah pengimplementasian logo terhadap beberapa media. Hal tersebut digunakan agar mengetahui tata cara penerapan logo dan tidak mengubah makna dari logo tersebut. Dalam perancangan ini menggunakan media utama dan pendukung. Media utama yang digunakan adalah logo dan GSM (Graphic Standard Manual). Media pendukung dan tools promotion yang digunakan ada 5, yaitu: stasionary, seragam, sepeda motor, paper bag, dan merchandise, sosial media, $x$-banner, katalog, dan brosur.

Hasil perolehan like dari pameran online yang diselenggarakan oleh STIKI sebesar 54. Kemudian berdasarkan deskripsi data kuantitatif diperoleh kesimpulan bahwa dari 25 responden memperoleh presentase sebesar $85 \%$ dan termasuk pada kualifikasi baik. Bedasarkan hasil tersebut dapat dikatakan bahwa produk logo sebagai media pengenalan IKM Batik Tulis Mandangin dapat dikatakan layak untuk dipublikasikan.

Perancangan corporate identity IKM Batik Tulis Mandangin memiliki hasil akhir berupa logo diharapkan mampu menjadi identitas IKM. Kedepannya, semoga identitas tersebut dapat membantu memperluas pemasaran. Perancang memilik banyak manfaat dari proses observasi lapangan, perancangan logo, dan kepenulisan tugas akhir. Untuk mahasiswa yang ingin melakukan perancangan dengan tema yang hampir sama sebaiknya lebih fokus pada perancangan media promosi. Hal tersebut dimaksudkan untuk membantu memperluas jangkauan pemasaran.

\section{Daftar Pustaka}

Argenti, Paul A. 2010. Komunikasi Korporat Edisi Lima. Translated by Putri Ailia Idris. kelima ed. Jakarta: Salemba Humanika.

Cholil, Akmal Musyadat. 2018. 101 Branding Ideas: Strategi Jitu Memenangkan Hati Konsumen. Anak Hebat Indonesia.

Darmaprawira, Sulasmi. 2002. Warna Teori dan Kreativitas Penggunaannya. Bandung: ITB. 
Ishwara, Helen, Supriyapto Yahya, and Xenia Moeis. 2011. Batik Pesisir pusaka Indonesia: koleksi Hartono Sumarsono. Jakarta: KPG (Kepustakaan Populer Gramedia).

Julita, Rosella, P Gogor Bangsa, and Hen Dian Yudani. 2013. "Perancangan Logo \& Corporate Identity Hotel Gowin Bali." Jurnal DKV Adiwarna 1 (2): 12. http://publication.petra.ac.id/index.php/dkv/article/view/747.

Kimbal, Rahel Widiawati. 2015. Modal Sosial dan Ekonomi Industri Kecil: Sebuah Studi Kualitatif. Yogyakarta: Deepublish.

Listya, Ariefika. 2019. "Konsep dan pengunaan warna dalam infografis." Jurnal Desain 6 (01): 1019. https://doi.org/10.30998/jurnaldesain.v6i01.2837.

Marijan, Kacung, and Nono Adya Supriyatno. 2013. Album Budaya 2013 : Batik Madura. edited by Idham Bachtiar Setiadi. Jakarta: Direktorat Jenderal Kebudayaan.

Muntazori, Ahmad Faiz, Ariefika Listya, and Muhammad Iqbal Qeis. 2019. "Branding Produk UMKM Pempek Gersang." Jurnal Desain 6 (03): 177-185. https://doi.org/10.30998/id.v6i3.4252.

Paramita, Yunda, and Tri Cahyo Kusumandyoko. 2019. "Perancangan Corporate Identity Batik Tulis Tenggeran Kota Probolinggo." Jurnal Seni Rupa 7 (1): 1-10. https://jurnalmahasiswa.unesa.ac.id/index.php/va/article/view/26676.

Parmono, Kartini. 2013. "Nilai kearifan lokal dalam batik tradisional Kawung." Jurnal Filsafat 23 (2): 134-146. https://doi.org/10.22146/jf.13217.

Sanyoto, Sadjiman Ebdi. 2006. Metode perancangan komunikasi visual periklanan. Yogyakarta: Dimensi Press.

Sugiyono. 2014. Metodologi Penelitian Kuantitatif, Kualitatif, Dan R\&D. Bandung: Alfabeta.

Wheeler, Alina. 2009. Designing Brand Identity: an Essential Guide for The Entire Branding Team. Hoboken. 3rd ed. New Jersey: John Willey \& Son.

Wijaya, Priscilia Yunita. 1999. "Tipografi dalam desain komunikasi visual." Nirmana 1 (1): 47-54. https://ojs.petra.ac.id/ojsnew/index.php/dkv/article/view/16040. 